\title{
ACCOUNTS
}

of chemical research

\section{The Chemistry of Aromatic Osmacycles}

\author{
XIAO-YU CAO, ${ }^{+}$QIANYI ZHAO, ${ }^{+}$ZHIQUN LIN, ${ }^{+, \neq, *}$ AND \\ HAIPING XIA ${ }^{\dagger, *}$ \\ 'State Key Laboratory of Physical Chemistry of Solid Surfaces and Department of \\ Chemistry, College of Chemistry and Chemical Engineering, Xiamen University, \\ Xiamen 361005, China, and ${ }^{\ddagger}$ School of Materials Science and Engineering, \\ Georgia Institute of Technology, Atlanta, Georgia 30332, United States
}

RECEIVED ON APRIL 19, 2013

\section{CONSPECTUS}

A romatic compounds, such as benzene and its derivatives, porphyrins, fullerenes, carbon nanotubes, and graphene, have numerous applications in biomedicine, materials science, energy science, and environmental science. Metalla-aromatics are analogues of conventional organic aromatic molecules in which one of the (hydro)carbon segments is formally replaced by an isolobal transition-metal fragment. Researchers have studied these transition-metalcontaining aromatic molecules for the past three decades, particularly the synthesis and reactivity of metallabenzenes. Another focus has been the preparation and characterization of other metalla-aromatics

\section{types of osmacycles in the Xia group}

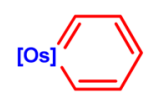<smiles>C1=C[GeH2]C=CC1</smiles><smiles></smiles><smiles>C1=C[GeH]=N[GeH]=C1</smiles><smiles>C1=CO[GeH2]O1</smiles><smiles>c1ccc2ccccc2c1</smiles><smiles>c1ccc2ccccc2c1</smiles><smiles></smiles><smiles>c1ccc2cnccc2c1</smiles><smiles></smiles><smiles></smiles>
such as metallafurans, metallapyridines, metallaben-

zynes, and more. Despite significant advances, remaining challenges in this field include the limited number of convenient and versatile synthetic methods to construct stable and fully characterized metalla-aromatics, and the relative shortage of new topologies.

To address these challenges, we have developed new methods for preparing metalla-aromatics, especially those possessing new topologies. Our synthetic efforts have led to a large family of closely related metalla-aromatics known as aromatic osmacycles. This Account summarizes the synthesis and reactivity of these compounds, with a focus on features that are different from those of compounds developed by other groups. These osmacycles can be synthesized from simple precursors under mild conditions. Using these efficient methods, we have synthesized aromatic osmacycles such as osmabenzene, osmabenzyne, isoosmabenzene, osmafuran, and osmanaphthalene. Furthermore, these methods have also created a series of new topologies, such as osmabenzothiazole and osmapyridyne. Our studies of the reactivity of these osma-aromatics revealed unprecedented reaction patterns, and we demonstrated the interconversion of several osmacycles.

Like other metalla-aromatics, osma-aromatics have spectroscopic features of aromaticity, such as ring planarity and the characteristic bond lengths between a single and double bond, but the osma-aromatics we have prepared also exhibit good stability towards air, water, and heat. Indeed, some seemingly unstable species proved stable, and their stability made it possible to study their optical, electrochemical, and magnetic properties. The stability of these compouds results from their aromaticity and the phosphonium substituents on the aromatic plane: most of our osma-aromatics carry at least one phosphonium group. The phosphonium group offers stability via both electronic and steric mechanisms. The phosphonium acts as an electron reservoir, allowing the circulation of electron pairs along metallacycles and lowering the electron density of the aromatic rings. Meanwhile, the bulky phosphonium groups surrounding the aromatic metallacycle prevent most reactions that could decompose the skeleton.

\section{Introduction}

Aromaticity is an important concept in organic chemistry. The fruitful interplay of theory and experiment facilitates the molecular engineering of aromatic compounds, thereby providing numerous new compounds and materials with interesting properties. Formal replacement of one $\mathrm{CH}$ group in benzene by a main group element provides aromatic analogues of benzene (for instance in pyridine one $\mathrm{CH}$ 
CHART 1

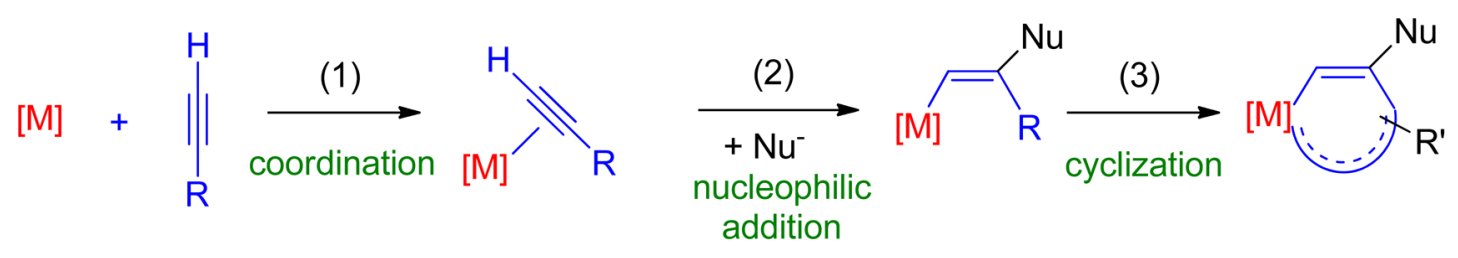

\section{SCHEME 1}

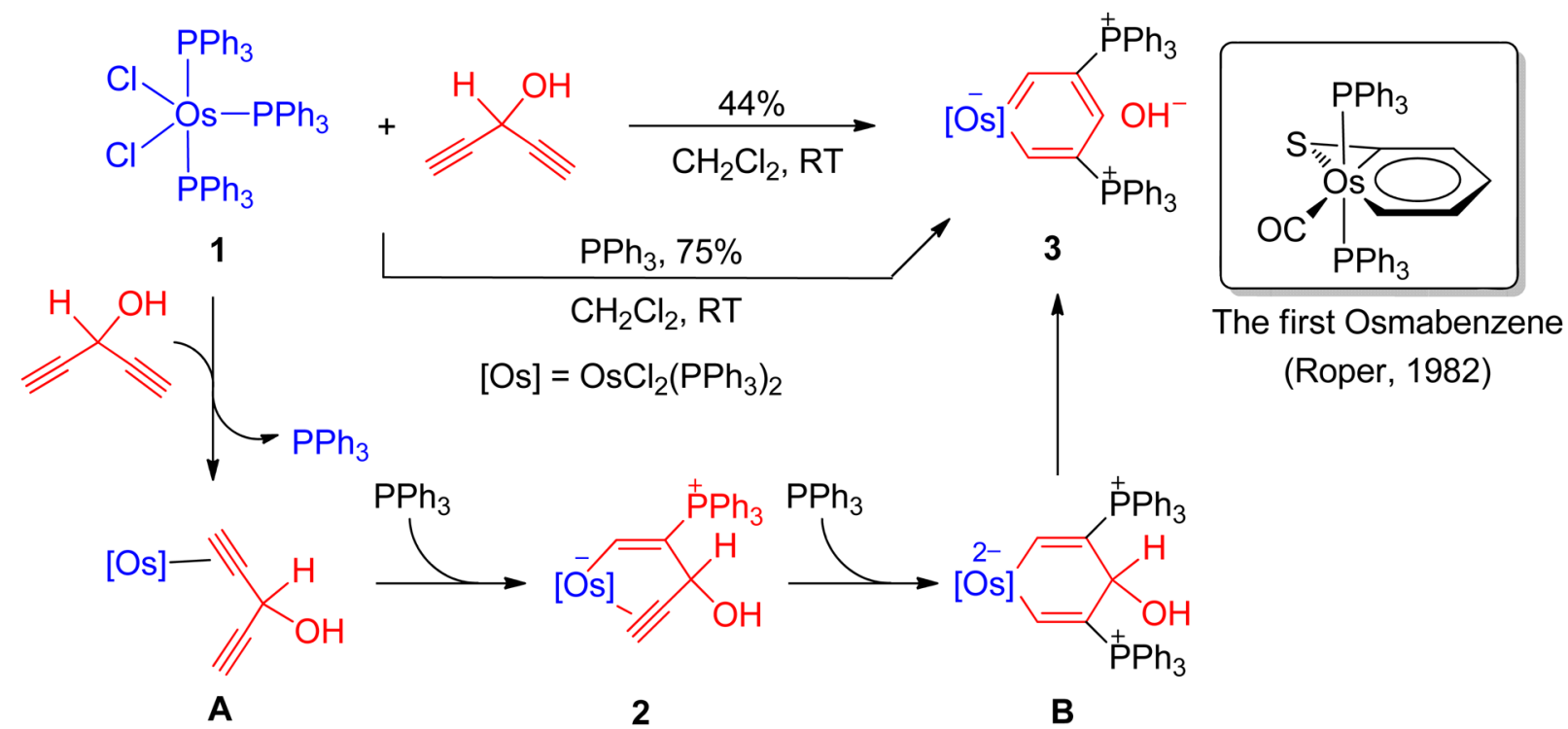

group is replaced by a $\mathrm{N}$ atom). Likewise, formal replacement of the $\mathrm{CH}$ group by an isolobal transition metal fragment yields "metallabenzenes".

In the past 30 years, significant progress has been made in the synthesis and reactivity of metallabenzenes. ${ }^{1-5}$ Since the theoretical prediction by Thorn and Hoffmann in $1979^{6}$ and the first preparation of an osmabenzene by Roper et al. in $1982,{ }^{7}$ stable metallabenzenes with different metals have been prepared. ${ }^{1-5}$ The flurry of activity has also expanded to other topologies of aromatic metallacycles, ${ }^{5,8,9}$ moving the field forward from metallabenzenes to metalla-aromatics.

Since 2004, we have concentrated on the development of synthetic strategies for metalla-aromatics, with a particular focus on their reactivity that would lead to new metallaaromatic species. ${ }^{10}$ Our key ring-forming reactions of metalla-aromatics were characterized by the initial coordination of the alkyne to the metal center, followed by subsequent attack of nucleophiles (mostly triphenylphosphines, or anions such as $\mathrm{I}^{-}, \mathrm{SCN}^{-}$, and $\mathrm{Br}^{-}$) on the coordinated alkyne (Chart 1), and finally ring-closing through cycloaddition, $\mathrm{C}-\mathrm{H}$ activation, or coordination. Our efforts over the past 8 years have expanded the library of closely related osma-aromatics.
This Account seeks to highlight our contributions on osmaaromatics, focusing particularly on their synthesis, reactivity, and stability resulting from aromaticity and phosphonium substituents. The aromatic features of the osmacycles, be it theoretical (by different calculations) ${ }^{11,12}$ or experimental (planar $\pi$-skeleton and negligible bond alternation in crystal structures for instance), will not be discussed here but could be found in greater detail in theoretical reviews ${ }^{11,12}$ or corresponding articles for each osmacycle. Furthermore, we make no attempt to cover comprehensively the history of metallaaromatics and seminal work from many other researchers in this field but rather refer the reader to some relevant literature. ${ }^{1,2,4,8,9,13,14}$

\section{Osmabenzene}

The first metallabenzene was prepared from the reaction of Os(CS)(CO)( $\left(\mathrm{PPh}_{3}\right)_{3}$ and ethyne (Scheme 1, right). ${ }^{7}$ Thereafter, the field of metalla-aromtics flourished with significant development of synthetic methods to yield metallabenzenes with different metals. However, Roper's method remained the only pathway to osmabenzenes. ${ }^{1}$ In close collaboration with Jia et al. from Hong Kong University of Science and 


\section{SCHEME 2}

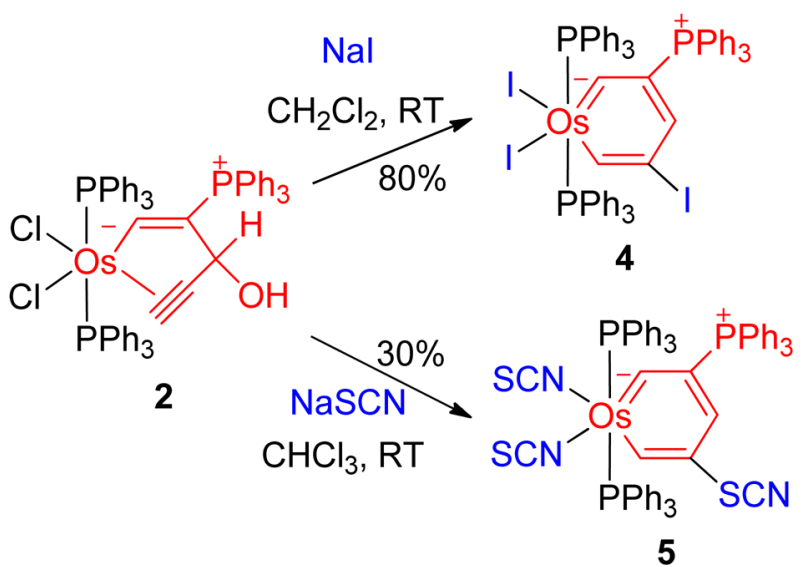

Technology, we developed the second route to stable osmabenzenes. ${ }^{10}$ We found that the reaction of $\mathrm{OsCl}_{2}\left(\mathrm{PPh}_{3}\right)_{3}$ with readily accessible 1,4-pentadiyn-3-ol produced bisphosponium-substituted osmabenzene $\mathbf{3}$ at room temperature (Scheme 1). When $\mathrm{PPh}_{3}$ was added to the reaction mixture, the isolated yield of 3 was increased from $44 \%$ to $75 \%$. The proposed mechanism for this reaction involved initiation with the substitution of a coordinated phosphine ligand with an $\eta^{2}$-coordinated alkyne to form intermediate $\mathbf{A}$, followed by nucleophilic attack of the $\mathrm{PPh}_{3}$ at the coordinated alkyne to furnish intermediate $\mathbf{2}$. Another $\mathrm{PPh}_{3}$ attacked $\mathbf{2}$ to give intermediate $\mathbf{B}$, which then lost $\mathrm{OH}^{-}$from the $\mathrm{sp}^{3}$-carbon on the $\gamma$ position to yield osmabenzene $\mathbf{3}$.

We then tried to isolate the intermediates of this reaction. In situ NMR spectroscopy indicated that several new species along with osmabenzene $\mathbf{3}$ were produced initially, and osmabenzene 3 dominated eventually (Scheme 1). It was difficult to isolate these species directly from dichloromethane solution. Fortunately, however, intermediate 2 was precipitated as a yellow solid and isolated in good yield when the reaction was carried out in THF. Intermediate 2 was stable for weeks as a solid under nitrogen but became unstable in solution, especially in the presence of acid or base. It was also susceptible to nucleophiles other than $\mathrm{PPh}_{3}$ (Scheme 2). ${ }^{15}$ The addition of $\mathrm{Nal}$ to the solution of $\mathbf{2}$ gave iodoosmabenzene $\mathbf{4}$, representing a rare halogen-substituted metallabenzene. Accordingly, the addition of NaSCN yielded osmabenzene $\mathbf{5}$. Iodoosmabenzene $\mathbf{4}$ was synthetically interesting because it may undergo a series of crosscoupling reactions. Intermediate $\mathbf{2}$ and osmabenzene $\mathbf{5}$ were important starting materials for a series of reactions described below.

Geometrically, the construction of a six-membered metallacycle from two components has three possible
CHART 2

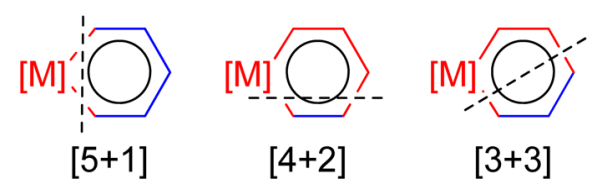

retrosyntheses: [5 +1$]$, [4 4 ], and [3+3] (Chart 2). The synthesis of osmabenzenes 3-5 represented the most straightforward [5 +1$]$ approach to metallabenzenes, starting from a metal complex and a commercially available $C_{5}$ segment under ambient conditions at room temperature. The reactions were completed in one pot and can easily be scaled up to gram quantities. This strategy is general and robust as reflected not only by the structural diversity of osmabenzene products (e.g., 3, 4, and 5) or organic starting materials (e.g., the synthesis of osmabenzene $\mathbf{1 0}^{16}$ and osmatoluene 14, ${ }^{17}$ see below) but also by the synthesis of stable ruthenabenzene. ${ }^{18}$

Osmabenzene $\mathbf{3}$, the first member of the osma-aromatic family developed by us, exhibited several unique characteristics. The presence of bulky and electron-deficient phosphonium substituents on the metalla-aromatic plane distinguished our osma-aromatics from those developed by other groups (Scheme 1), ${ }^{7,19-21}$ resulting in differences in spectroscopy, properties, and reactivity. For instance, the ortho proton of osmabenzene 3 resonated at $23.13 \mathrm{ppm}$, significantly farther downfield than that in Roper's first osmabenzene (13.95 ppm). ${ }^{7}$ This downfield shift was mainly due to the electron-withdrawing effect of phosphonium substituents. When the electronic effect became less intense, as in osmabenzene $\mathbf{4}$, which carried only one phosphonium group, the proton resonances of the metallacycle shifted back to upfield (20.1 ppm for OsCHCl and $19.0 \mathrm{ppm}$ for $\mathrm{OsCHCPPh}_{3}$ ). The X-ray diffraction data revealed that the metallacycle of $\mathbf{3}$ was essentially a planar ring structure similar to Roper's osmabenzene, and the $\mathrm{C}-\mathrm{C}$ bond distances of the metallacycle were longer than typical $\mathrm{C}=\mathrm{C}$ double bonds and shorter than typical $\mathrm{C}-\mathrm{C}$ single bonds. ${ }^{7}$ Nonetheless, the Os-C bond lengths were shorter than those of Roper's osmabenzene. ${ }^{7,22}$ Four resonance structures of osmabenzene $\mathbf{3}$ were proposed (Chart 3). The similarity in $\mathrm{P}-\mathrm{C}$ (phenyl) and $\mathrm{P}-\mathrm{C}$ (metallabenzene) bond lengths suggested that $\mathbf{3 A}$ and $\mathbf{3 B}$ were the dominant contributors to the overall structure in the solid state; however, cyclically unconjugated $\mathbf{3 C}$ and 3D may influence the reactivity of osmabenzene $\mathbf{3}$ in solution and contribute to the stability of 3. Our osma-aromatics usually possessed good air and thermal stability. For instance, osmabenzene $\mathbf{3}$ 


\section{CHART 3}

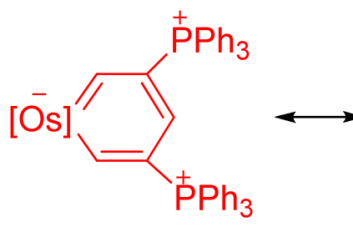

3A

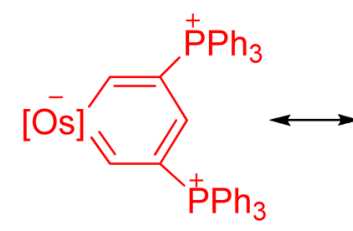

$3 B$

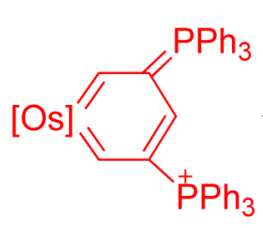

3C

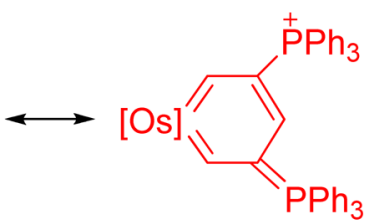

3D

$[\mathrm{Os}]=\mathrm{OsCl}_{2}\left(\mathrm{PPh}_{3}\right)_{2}$

can be kept for months without appreciable decomposition in the solid state at room temperature; its solid sample remained unchanged after being heated at $120{ }^{\circ} \mathrm{C}$ for $24 \mathrm{~h}$ in air. Such stability greatly facilitated the synthesis, purification, characterization, and storage of our osma-aromatics.

The unique function of the phosphonium group can be understood in two ways: electronic and steric. Acting as an electron reservoir, the phosphonium allows the circulation of electron pairs along metallacycles and lowers the electron density of aromatic ring (Chart 3; 3C and 3D). The capability of phosphonium to accept electrons also makes the $\beta$-carbon of phosphonium group electrophilic. The bulky $\mathrm{PPh}_{3}$ groups surrounding aromatic metallacycle prevent most possible reactions that may decompose the skeleton.

The reaction of intermediate $\mathbf{2}$ with acetic acid afforded highly insoluble $\alpha, \beta$-unsaturated ketone complex $\mathbf{6}$ as a red solid, which precipitated from the solution (Scheme 3). ${ }^{23}$ When 6 was treated with excess $\mathrm{PMe}_{3}$, two $\mathrm{PPh}_{3}$ ligands and a chloride ligand of $\mathbf{6}$ were substituted by $\mathrm{PMe}_{3}$ ligands to yield $\mathbf{7}$ (Scheme 3). Interestingly, $\mathbf{7}$ was slowly isomerized to p-osmaphenol 8 in chloroform solution (Scheme 3). The difference in the stability of $\mathbf{6}$ and $\mathbf{7}$ was presumably related to the decreased electron density of the metal cycle in the latter due to the replacement of one $\mathrm{Cl}^{-}$ligand with $\mathrm{PMe}_{3}$ ligand, thus facilitating the deprotonation of the terminal $\alpha-\mathrm{H}$ of the coordinated olefin. In comparison with previous metallaphenol ${ }^{7}$ and the organic phenol derivatives, osmaphenol 8 was air-stable in both the solution and the solid state. The chloroform solution of $\mathbf{8}$ remained unchanged in air for over 1 week.

Motivated by the successful synthesis of our first osmabenzene, we extended the organic substrate to the alternatives of 1,4-pentadiyn-3-ol, with a lower degree of unsaturation, and found osmabenzenes could still be obtained. The reaction of $\mathrm{OsCl}_{2}\left(\mathrm{PPh}_{3}\right)_{3}$ with 1-pentyn-4-en-3-ol in THF produced the $\eta^{2}$-allyl alcohol complex $\mathbf{9}$ (Scheme 4). ${ }^{16}$ Similar to $\mathbf{2}$, this reaction was also initiated with the coordination of the alkyne to the metal center and nucleophilic
SCHEME 3
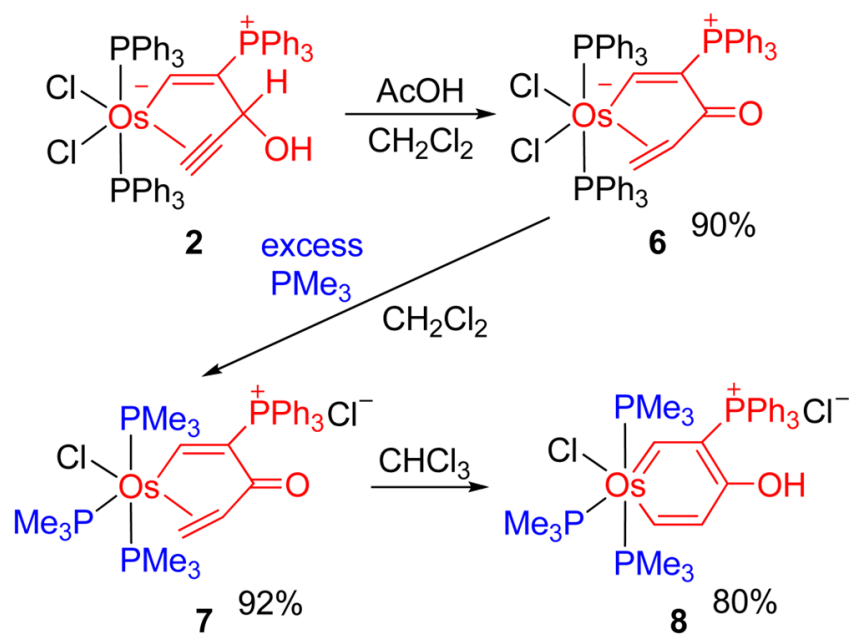

attack by phosphines on the coordinated alkyne. Heating 9 in dichloromethane with reflux led to the formation of monophosphonium substituted osmabenzene 10, $\eta^{2}$-allene complex 11, and other species (Scheme 4). Notably, 10 and 11 were isomers. The formation of osmabenzene 10 involved the dissociation of $\mathrm{OH}^{-}$from 9 and subsequent $\alpha-\mathrm{H}$ deprotonation; thus the addition of $\mathrm{NaHCO}_{3}$ increased the yield of 10 from $28 \%$ to $43 \%$.

Although the reaction of $\mathrm{OsCl}_{2}\left(\mathrm{PPh}_{3}\right)_{3}$ with commercially available 3-methyl-1-pentyn-4-en-3-ol proceeded well to give intermediate 12 (Scheme 5 ), ${ }^{17}$ the pathway to osmabenzene was more problematic. The $\mathrm{PMe}_{3}$ substitution of 12 led to complex $\mathbf{1 5}$, but unlike $\mathbf{7}$, which was gradually isomerized to osmaphenol $\mathbf{8}$, no anticipated osmatoluene was observed under the same conditions. The contrasting outcomes of structurally similar $\mathbf{7}$ and $\mathbf{1 5}$ were probably due to the different electronic nature of the exocyclic group on the $\gamma$-carbon of the metallacycle of these two complexes because the ketone in $\mathbf{7}$ was more electron-withdrawing than the alkene in 12. The replacement of two $\mathrm{Cl}^{-}$in the neutral complex 12 by two benzonitriles led to dicationic complex 13 (Scheme 5). The electron density of the 


\section{SCHEME 4}

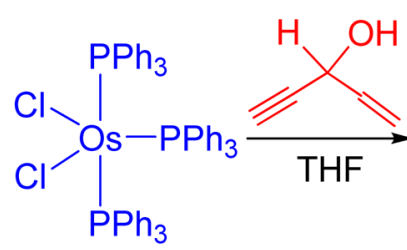

1<smiles>OC1C=CC=C1[Pb]</smiles>

$65 \%$
$\underset{\mathrm{CH}_{2} \mathrm{Cl}_{2} \text {, reflux }}{\stackrel{\mathrm{NaHCO}_{3}}{\longrightarrow}}$

$[\mathrm{Os}]=\mathrm{OsCl}_{2}\left(\mathrm{PPh}_{3}\right)_{2}$

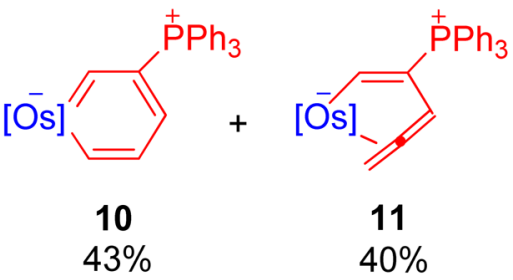

$40 \%$

\section{SCHEME 5}
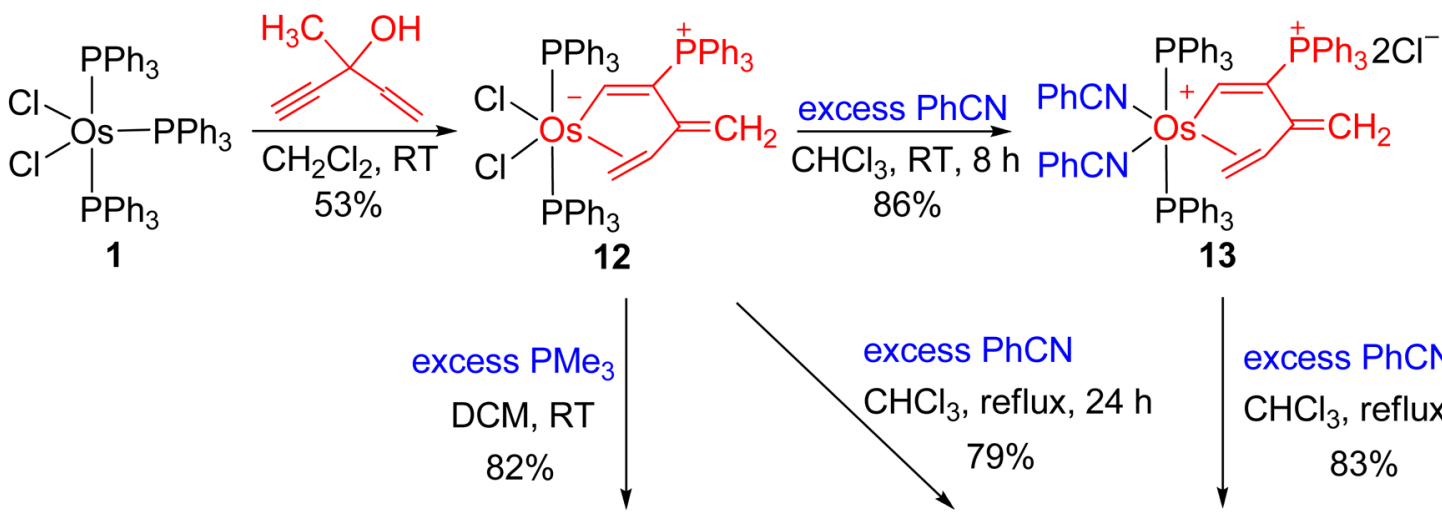

excess PhCN

$\mathrm{CHCl}_{3}$, reflux, $12 \mathrm{~h}$

$83 \%$
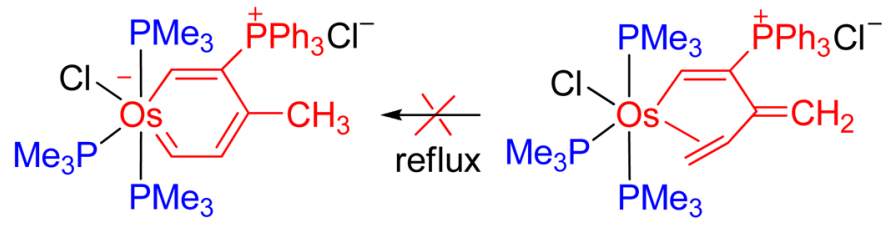

15

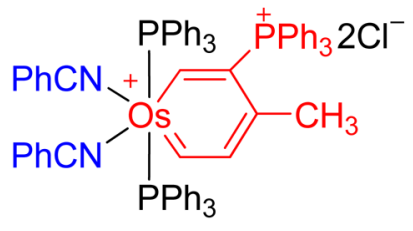

14 osmacycle was significantly decreased as a direct consequence of ligand exchange, thus facilitating the hydrogentransfer process for the formation of osmatoluene $\mathbf{1 4}$ from 13 (Scheme 5). The allene complex 13 was then isomerized almost quantitatively to give osmatoluene $\mathbf{1 4}$.

The reactivity of metallabenzenes is a result of the presence of an aromatic ring and a reactive metal center and was explored first by Roper, Wright and co-workers. ${ }^{24}$ Although metallabenzenes tend to react in ways that are atypical of conventional aromatic molecules, ${ }^{4}$ Roper, Wright and co-workers demonstrated the first electrophilic aromatic substitution of metallabenzene with an osmabenzene. ${ }^{24}$ The directing effects in these reactions were in accordance with those of benzene.

Arenes, in particular heteroarenes, can undergo nucleophilic aromatic substitution $\left(\mathrm{S}_{\mathrm{N}} \mathrm{Ar}\right)$ reactions if electron-withdrawing groups are ortho or para to the leaving group (typically a halogen) on the ring. Nonetheless, the conditions for $S_{N} A r$ reactions are usually harsh. We reported the first
$\mathrm{S}_{\mathrm{N}} \mathrm{Ar}$ reaction of metallabenzene under ambient conditions. ${ }^{25}$ Osmabenzene 5 reacted with $\mathrm{MeONa} / \mathrm{MeOH}$ to generate osmabenzothiazole $\mathbf{1 6}$ (Scheme 6). The proposed mechanism revealed that the addition reaction of $\mathbf{5}$ with MeONa gave intermediate $\mathbf{C}$, which then underwent intramolecular nucleophilic attack to afford intermediate $\mathbf{D}$. The intermediate D can be regarded as a JacksonMeisenheimer complex. ${ }^{26}$ The phosphonium group acted as an electron reservoir, creating a more stable resonance form of $\mathbf{D}$ and the intermediate $\mathbf{E}$. The electron was then pushed back from the phosphonium group, driving the loss of the hydride ion and furnishing osmabenzothiazole $\mathbf{1 6}$. The mechanism involved a similar addition-elimination manner to the classic $S_{N} A r$ reactions of arenes. But unlike the tough conditions required for the classic reactions, the presence of the phosphonium substituent and the osmium center effectively lowered the electron density of the aromatic metallacycle, thus rendering the $S_{N} A r$ reaction and the leaving of $\mathrm{H}^{-}$able to proceed under ambient conditions. 


\section{SCHEME 6}<smiles>N#CSc1cc([Pb])cc(Sc2ccccc2)c1</smiles>

5

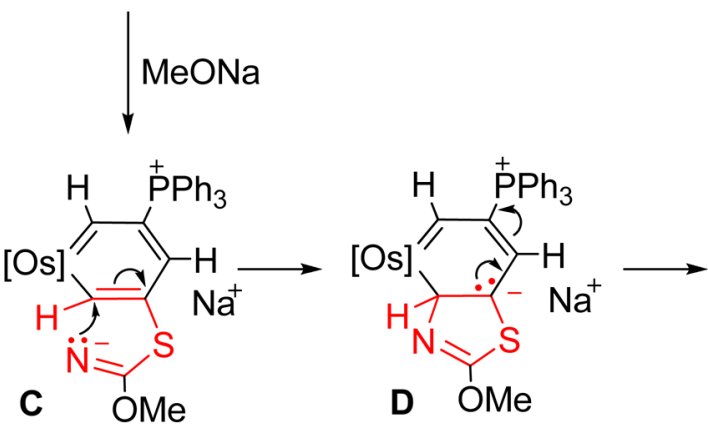<smiles></smiles>

16

$\mathrm{MeOH}$<smiles>COCC(C)C(C)O[Na]</smiles>

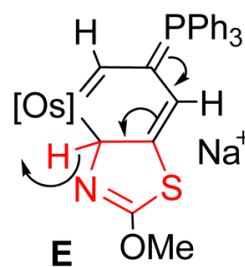

SCHEME 7

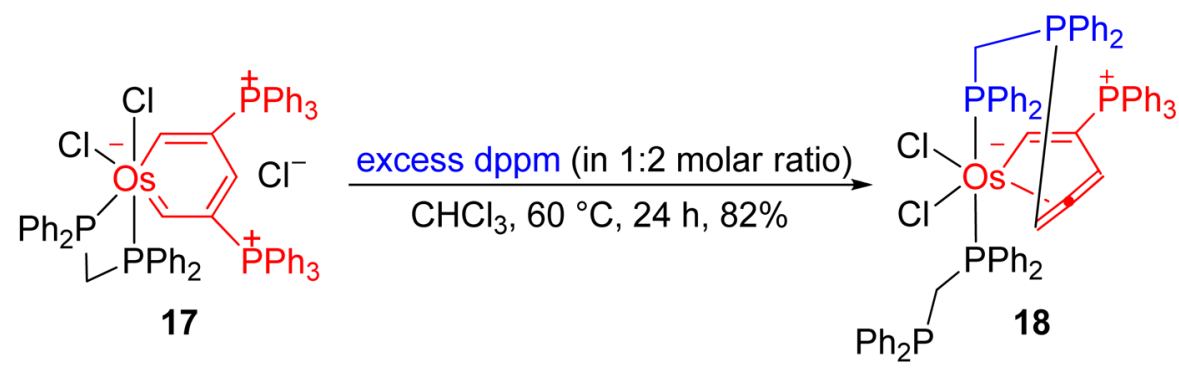

This reaction, using metallabenzene as a starting material, realized the annulation reaction of metallabenzenes, thus representing a novel pathway to construct fused metaIla-aromatics. It also demonstrated the aromaticity of osmabenzene.

When osmabenzene $\mathbf{3}$ was treated with an excess of the nuceophile bis(diphenylphosphino)methane (dppm), bisphosphonium substituted osmabenzene $\mathbf{1 7}$ was first obtained, which then underwent intramolecular nucleophilic addition and subsequent cleavage of the $\mathrm{P}-\mathrm{C}$ bond to give a cyclic osmium $\eta^{2}$ allene complex 18 (Scheme 7). ${ }^{27}$ Similar reactions also took place in ruthenabenzene and osmapyridinium.

While Scheme 7 depicted that osmabenzene can be converted to an allene complex, Scheme 8 showed that the alternative was also possible. ${ }^{17}$ Investigation of the conversion of $\mathbf{1 3}$ to osmabenzene $\mathbf{1 4}$ (Scheme 8) revealed that 13 underwent double bond shifting to generate the allene complex 19 at room temperature. Upon heating with reflux, complex $\mathbf{1 9}$ was transformed to osmabenzene 14 through an intermolecular proton-transfer process.

Recently, we achieved the interconversion of osmabenzenes and cyclic osmium $\eta^{2}$ allene complexes on the same system (Scheme 9). ${ }^{28}$ In the presence of excess $\mathrm{PPh}_{3}$ and $\mathrm{NaOH}$, osmabenzene 20 evolved into $\eta^{2}$-allene-coordinated complex 21, and $\mathrm{NaOH}$ presumably facilitated the $\mathrm{P}-\mathrm{C}$ bond cleavage of the metallacycle. The treatment of complex 21 with excess $\mathrm{PPh}_{3}$ in the presence of acid produced mono(8-hydroxyquinoline)-substituted osmabenzene 22, and with the excess 8-hydroxyquinoline under air, di(8-hydroxyquinoline)-substituted osmabenzene $\mathbf{2 3}$ was obtained. Both reactions involved intramolecular nucleophilic substitutions.

The ligand substitution reactions of osmabenzene $\mathbf{3}$ led to a series of new osmabenzenes $\mathbf{2 5 - 2 7}$ (Scheme 10). ${ }^{15}$ The electron density of aromatic metallacycles can be tuned through ligand exchange, thereby resulting in different reactivity and physical properties. The replacement of one $\mathrm{Cl}^{-}$with a pyridine or a ${ }^{-} \mathrm{N}(\mathrm{CN})_{2}$ (coordinated through $\mathrm{N}$ in 


\section{SCHEME 8}

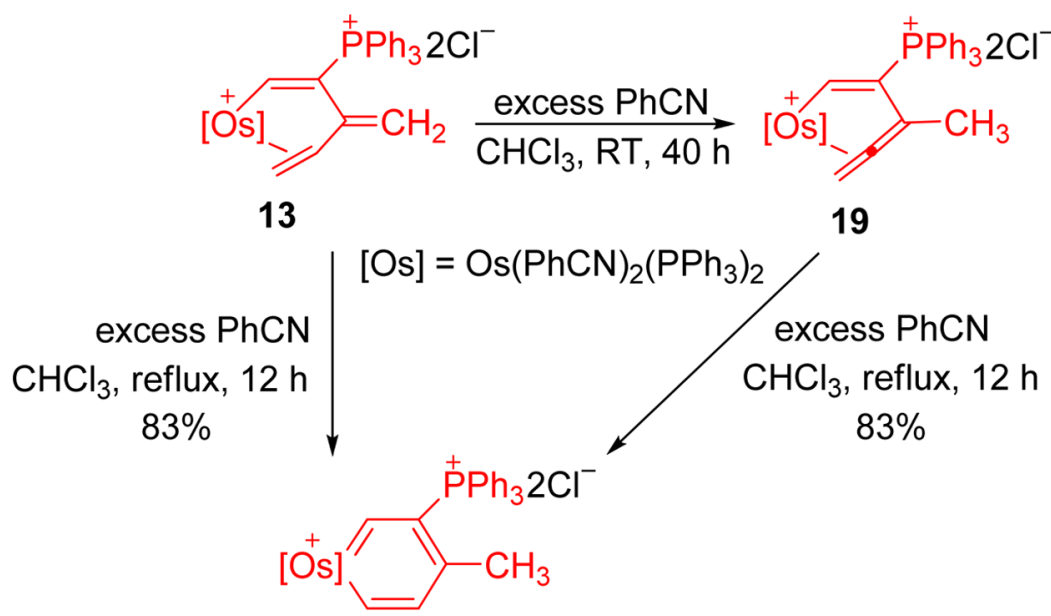

14

SCHEME 9

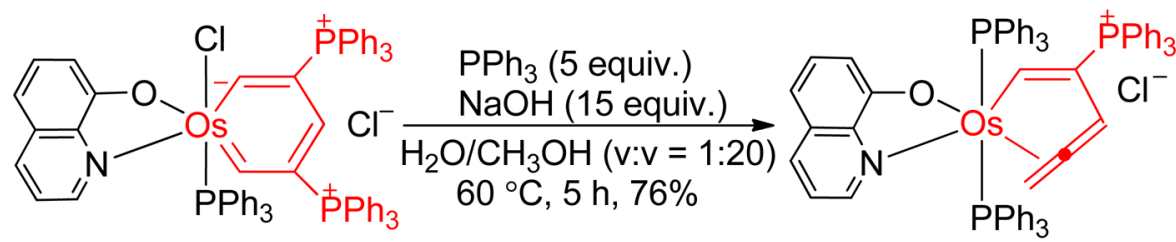

20
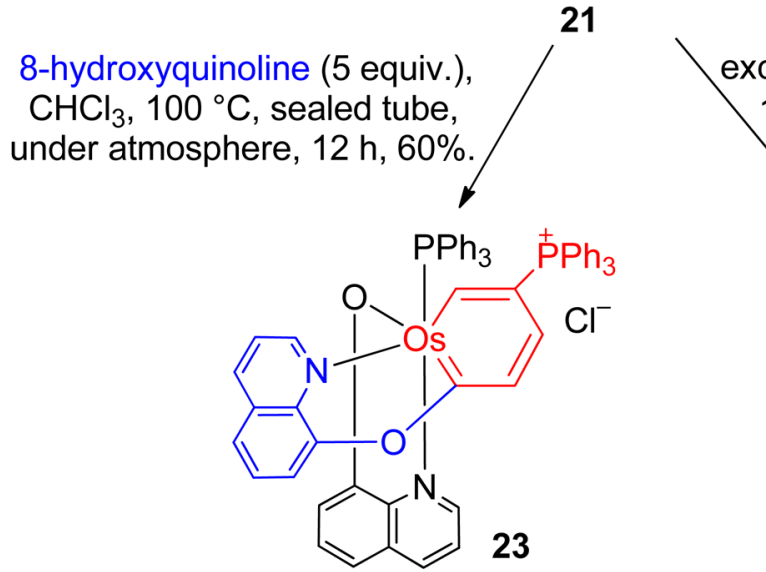

excess $\mathrm{PPh}_{3}, \mathrm{HCl}, \mathrm{CHCl}_{3}$, $100{ }^{\circ} \mathrm{C}$, sealed tube, 12 h, $55 \%$.

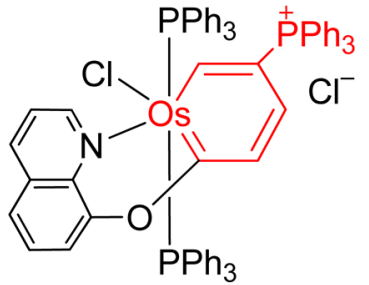

the $\mathrm{CN}$ ) produced monosubstituted osmabenzenes 25a and 25b. The reaction of $\mathbf{3}$ with NaSCN or excess NaN$(\mathrm{CN})_{2}$, on the other hand, led to the replacement of two $\mathrm{Cl}^{-}$, giving disubstituted osmabenzenes 26a and 26b. When the monodentate ligands were changed to bidentate ligands 2,2'-dipyridine or 1,10-phenanthroline, osmabenzenes $\mathbf{2 7 a}$ and $\mathbf{2 7} \mathbf{b}$ were formed. Note that the metallacycle of 27a deviates significantly from planarity, the osmium center was $0.6748 \AA$ out of the plane of the metallacyclic carbon atoms. The nonplanarity induced by bis-substitution was presumably due to both electronic and steric factors induced by the asymmetrical ligand environment above and below the six-membered metallacycle. $^{29}$

The ligand substitution reaction of osmabenzene $\mathbf{3}$ with various diisocyanides afforded a series of diisocyanidebridged bisosmabenzenes 28a-d (Scheme 11). ${ }^{30}$ Bisosmabenzenes containing $\mathrm{a} \mathrm{Cl}^{-}$and a phosphonium substitutent on each metallacycle $\mathbf{2 9 a}-\mathbf{d}$ were obtained from the reactions of intermediate $\mathbf{2}$ with diisocyanides in the presence of $\mathrm{NH}_{4} \mathrm{PF}_{6}$ and $\mathrm{NaCl}$ through nucleophilic addition reactions. Cyclic voltammetry of osmabenzenes $\mathbf{2 9 a}$-d indicated that the two metal centers in osmabenzenes 29c and 29d could interact with each other through the diisocyanide bridge. 
SCHEME 10

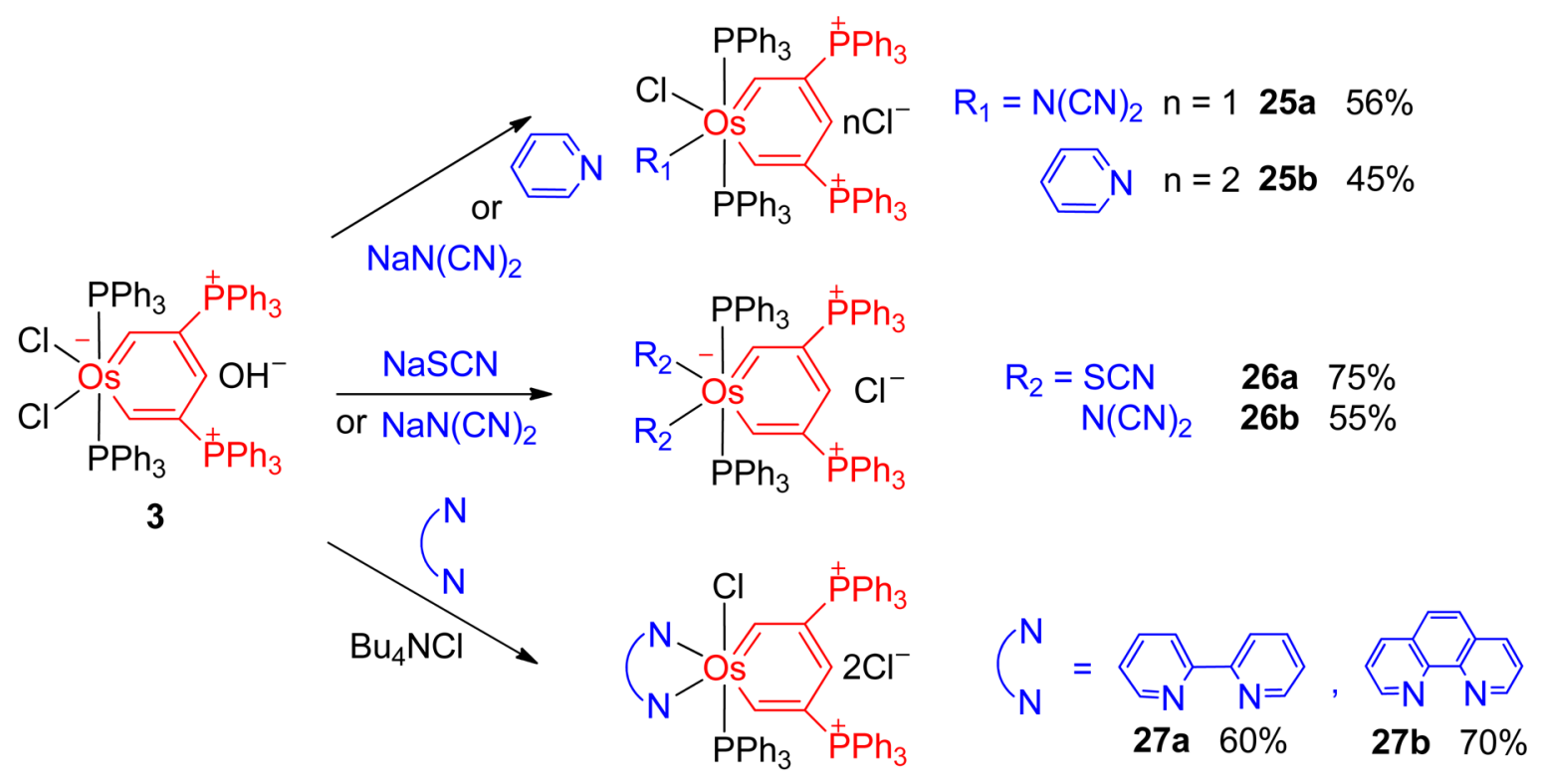

\section{SCHEME 11}

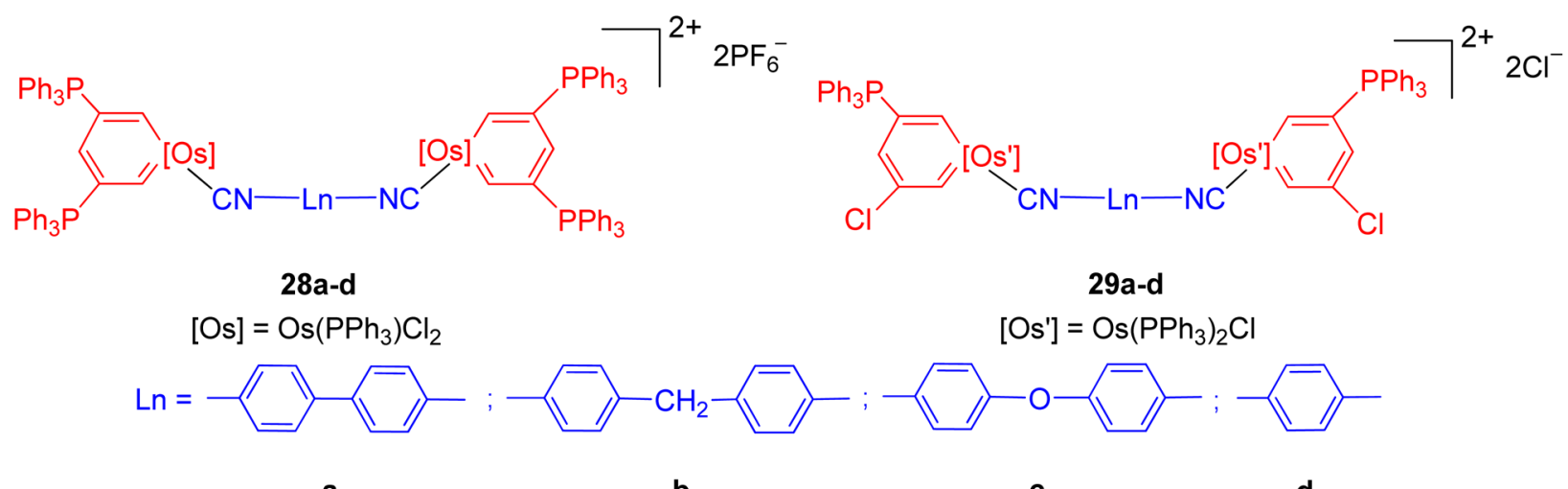

a

\section{Osmabenzyne and Isoosmabenzene}

Benzyne is a well-known yet transient intermediate involved in a wide variety of chemical transformations. Therefore, isolation and full characterization of metallabenzyne seems impossible at first glance. Nonetheless, Jia et al. isolated the first stable osmabenzyne in 2001 (Scheme 12, lower left). ${ }^{31}$ Since then, the Jia group has developed a series of approaches toward metallabenzynes and explored their reactivity thoroughly. ${ }^{5,8,9}$

Esteruelas et al. prepared the first isometallabenzene (Scheme 12, right). ${ }^{32}$ In 2011, we capitalized on an unprecedented formal [3 +3$]$ cycloaddition reaction between osmium hydride vinylidene $\mathbf{3 1}$ and alkynols to prepare stable isoosmabenzenes $\mathbf{3 1 a}-\mathbf{c}$ (Scheme 12). ${ }^{33} \mathrm{We}$ then further expanded the organic substrate to $\mathrm{HC} \equiv$ $\mathrm{CCH}(\mathrm{OEt})_{2}$ and obtained an osmabenzyne $\mathbf{3 3}$ unexpectedly
(Scheme 12). ${ }^{34}$ The reaction started with a similar [3 +3$]$ cycloaddition process to an intermediate isoosmabenzene 32, which then eliminated an ethoxyl group to give a stable osmabenzyne $\mathbf{3 3}$. Isoosmabenzene $\mathbf{3 2}$ was stable in solution for several hours, thus allowing in situ NMR monitoring of the transformation from 32 to 33.

Note that osmabenzyne $\mathbf{3 3}$ was remarkably stable. It can survive heating in air at $120^{\circ} \mathrm{C}$ for $5 \mathrm{~h}$ in the solid state. It was also resistant to several acids, bases, terminal alkynes, and nucleophiles. Strong nucleophiles, nonetheless, could attack osmabenzyne $\mathbf{3 3}$ at C3 to restore isoosmabenzenes (34a $\mathbf{a}^{33}$ and 34b, Scheme 12) or open the metallacycles (35a and 35b, Scheme 12). Clearly, the formal interconversion of isometallabenzene and metallabenzyne (Scheme 12) was achieved. 
SCHEME 12

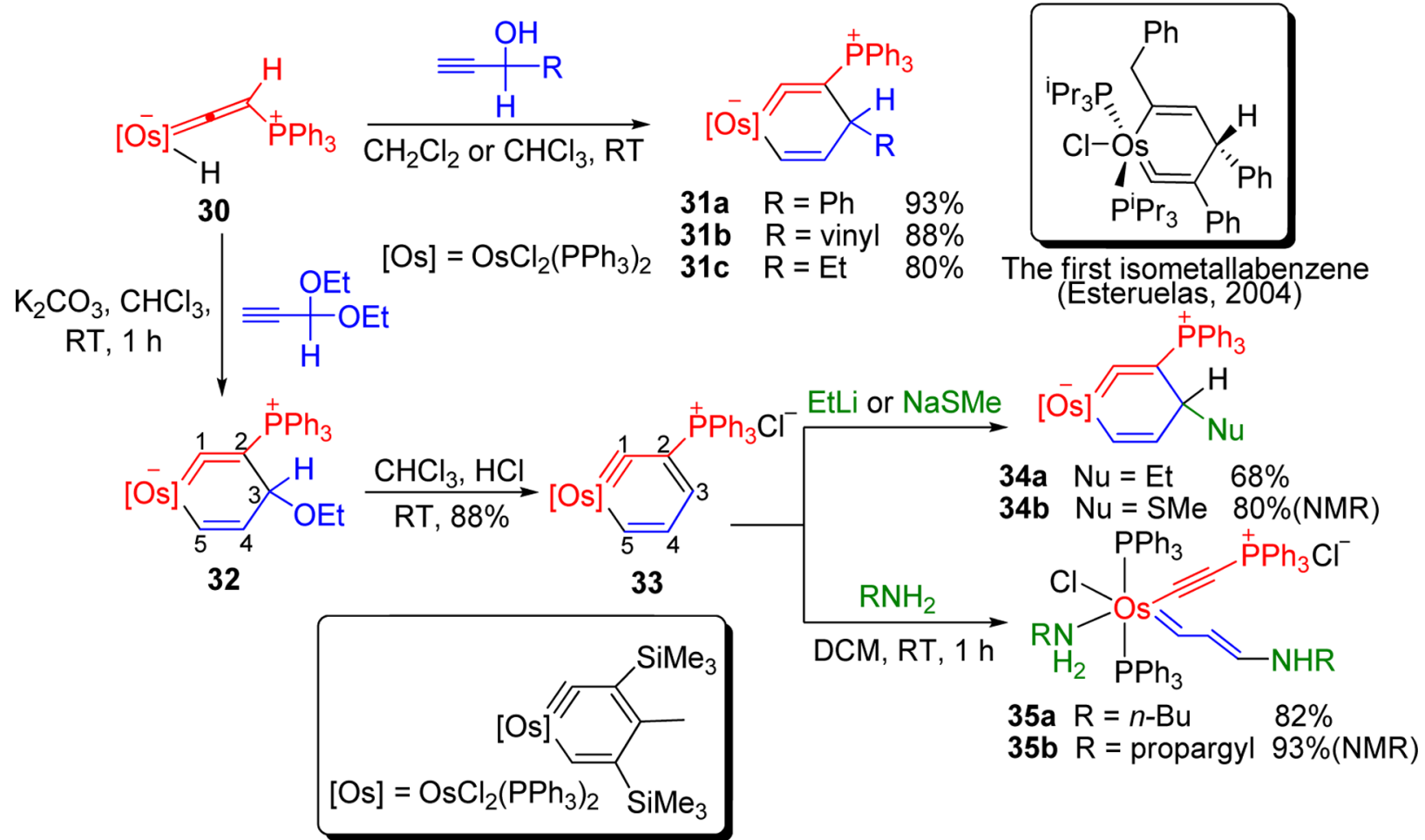

The first metallabenzyne

(Jia, 2001)

SCHEME 13<smiles></smiles>

36

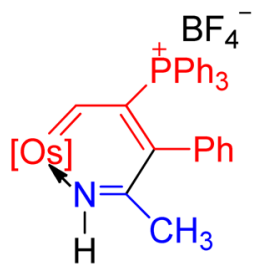

37

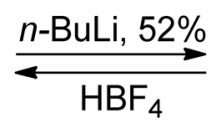

$\left[{ }^{-} \mathrm{s}\right]$<smiles>CC1=C(P)CCC1</smiles>

38

[Os] $=\mathrm{OsCl}_{2}\left(\mathrm{PPh}_{3}\right)_{2}$

\section{Osmapyridine and Osmapyridyne}

Although considerable progress has been made in the synthesis of metallabenzenes, their aza-containing analogue metallapyridine ${ }^{35,36}$ was significantly less developed. The first metallapyridine (tantalapyridine), which was not delocalized, was reported by Wigley et al. in $1998 .^{35}$ Note that our discovery in 2009 represented the second metallapyridine and the first metallapyridinium and osmapyridine. ${ }^{36}$

When complex 36 was mixed with $\mathrm{PPh}_{3}$ in acetonitrile under reflux, osmapyridinium $\mathbf{3 7}$ was obtained (Scheme 13). The reaction may be regarded as a formal hetero-DielsAlder reaction ${ }^{37}$ in which osmium hydride alkenylcarbyne 36 acted as 1-metalla-1,3-diene with acetonitrile as a dienophile. The deprotonation of $\mathbf{3 7}$ by $n$-BuLi produced osmapyridine $\mathbf{3 8}$, and the treatment of $\mathbf{3 8}$ with $\mathrm{HBF}_{4}$ regenerated 37 (Scheme 13). The construction of 36 can be considered as a [4 +2$]$ approach toward the six-membered metallapyridinium. Hence, we realized all three possible retrosyntheses to construct a six-membered matallacycle from the two constituents mentioned in Chart 2: [5 +1$]$, $[4+2]$, and [3 + 3].

Most notably, these osmapyridiniums are paramagnetic. Osmapyridinium $\mathbf{3 7}$ showed low-field chemical shifts for the ${ }^{1} \mathrm{H}$ NMR signals of $\mathrm{OsCH}(\delta=48.01)$ and $\mathrm{NH}(\delta=25.38)$. For osmapyridine 38, the ${ }^{31} \mathrm{P}$ NMR signals cannot be observed at room temperature or even at lower temperatures 
SCHEME 14

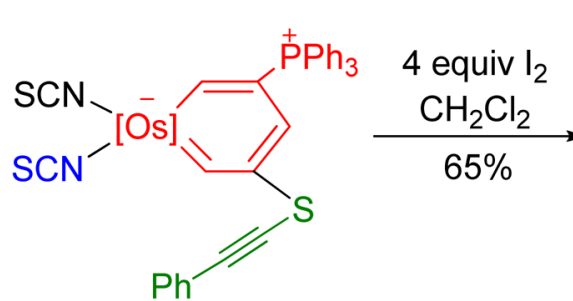

39

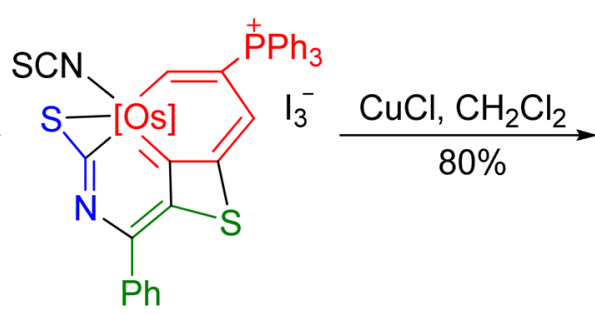

40

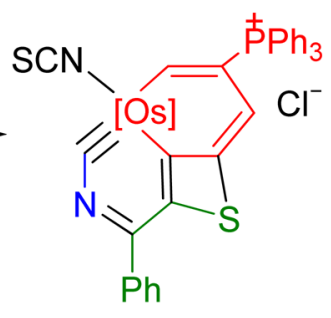

41

$[\mathrm{Os}]=\mathrm{Os}\left(\mathrm{PPh}_{3}\right)_{2}$

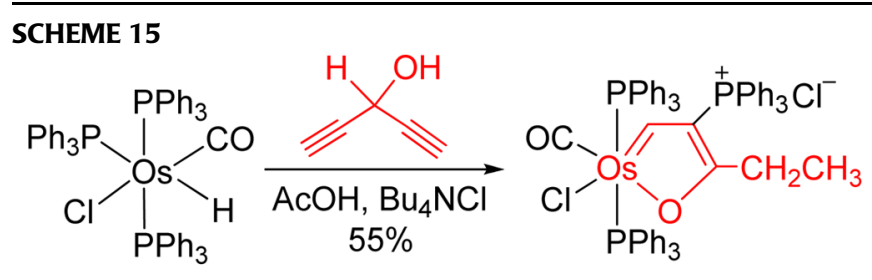

42

SCHEME 16

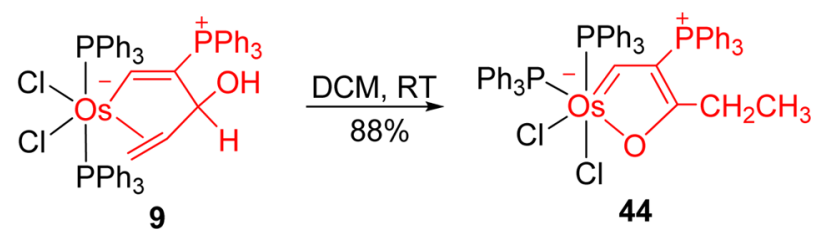

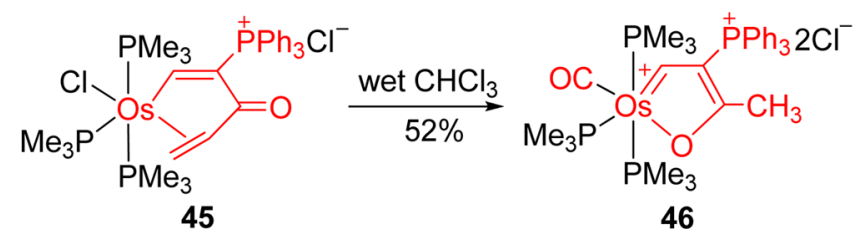

(200-293 K), while the ${ }^{1} \mathrm{H}$ NMR spectrum displayed several irregular broad signals at these temperatures. In addition, magnetic measurement experiments confirmed the paramagnetism of $\mathbf{3 7}$ and $\mathbf{3 8}$. The computational results indicated that the net spin populations primarily reside on the $0 s^{\mathrm{IV}}\left(5 d^{4}\right)$ center, and the Os-bonded $\mathrm{C}$ and $\mathrm{N}$ atoms also exhibited some paramagnetism. These paramagnetic centers could significantly modify the NMR behavior of the neighboring hydrogen atoms as observed in NMR spectroscopy. Note that $\mathbf{3 7}$ is the first metallapyridinium and $\mathbf{3 8}$ is the first late-transition-metal containing metallapyridine.

Recently, we synthesized the first $m$-metallapyridine (osmapyridine 40, Scheme 14, which can also be defined as an osmaisoquinoline) and the first metallapyridyne (osmapyridyne 41, Scheme 14). ${ }^{38}$ In comparison to the

two previously reported azametallabenzenes ${ }^{35,36}$ (i.e., $o$-metallapyridines in which the nitrogen atom was directly connected to the metal atom), osmapyridine $\mathbf{4 0}$ had its nitrogen atom only connected with carbon atoms. The treatment of osmabenzene $\mathbf{3 9}$ with $\mathrm{I}_{2}$ gave osmapyridine 40. The main structure of $\mathbf{4 0}$ was an osmium-bridged polycycle containing an osmabenzene ring and an $m$-osmapyridine ring. Surprisingly, copper(I) chloride can reduce complex $\mathbf{4 0}$ to osmapyridyne $\mathbf{4 1}$, the first metallapyridyne. The complexes $\mathbf{4 0}$ and $\mathbf{4 1}$ were metal-bridged polycyclic metallabenzenoid aromatics, in which the transitionmetal center was shared by both six-membered rings. Interestingly, the synthetic method permitted the use of metallabenzene as a starting material to prepare polycyclic metallaaromatics.

Notably, complexes 40 and 41 were stable in air and elevated temperatures. Solid samples of $\mathbf{4 0}$ and $\mathbf{4 1}$ can be heated at $100{ }^{\circ} \mathrm{C}$ in air for more than $5 \mathrm{~h}$ without noticeable decomposition. We also found that $\mathbf{4 1}$ did not react with common nucleophiles (e.g., $\mathrm{H}_{2} \mathrm{O}, \mathrm{MeOH}, \mathrm{MeONa}, \mathrm{KOH}$, and $\mathrm{NaSH}$ ) or electrophiles (e.g., $\mathrm{HCl}, \mathrm{HBF}_{4}, \mathrm{O}_{2}, \mathrm{Mel}$, and MeOTf).

\section{Osmafurans}

Osmafurans are the most extensively investigated fivemembered osma-aromatics. ${ }^{39}$ We found that complex 42 reacted readily with 1,4-pentadiyn-3-ol to give osmafuran 43 (Scheme 15). ${ }^{40}$ The $\eta^{2}$-allyl alcohol complex 9 yielded osmafuran 44 through a rearrangement in dichloromethane (Scheme 16). ${ }^{16}$ Osmafuran 46 was formed from complex 45 through complicated transformations, including the hydrolyzation of the terminal carbon-carbon double bond and removal of the carbonyl group (Scheme 16). ${ }^{41}$ Interestingly, because the osmium-carbon bond in complex osmafuran $\mathbf{4 7}$ showed obvious carbenic character, it underwent ring-expansion reactions through the alkyne insertion to produce nine-membered osmacycles $\mathbf{4 8}$ and 
SCHEME 17

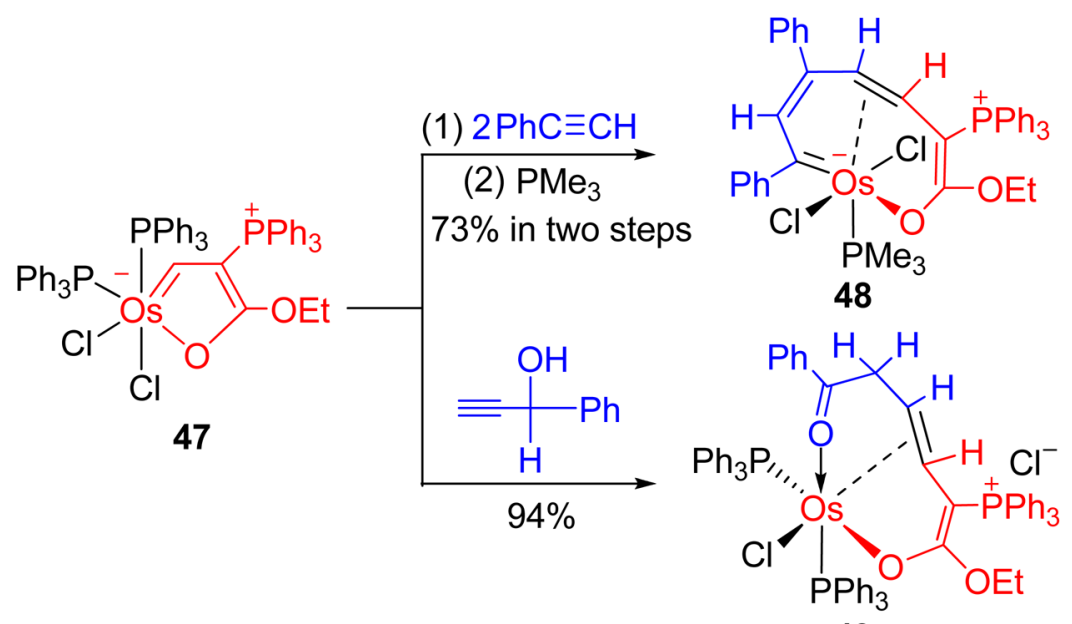

49

SCHEME 18
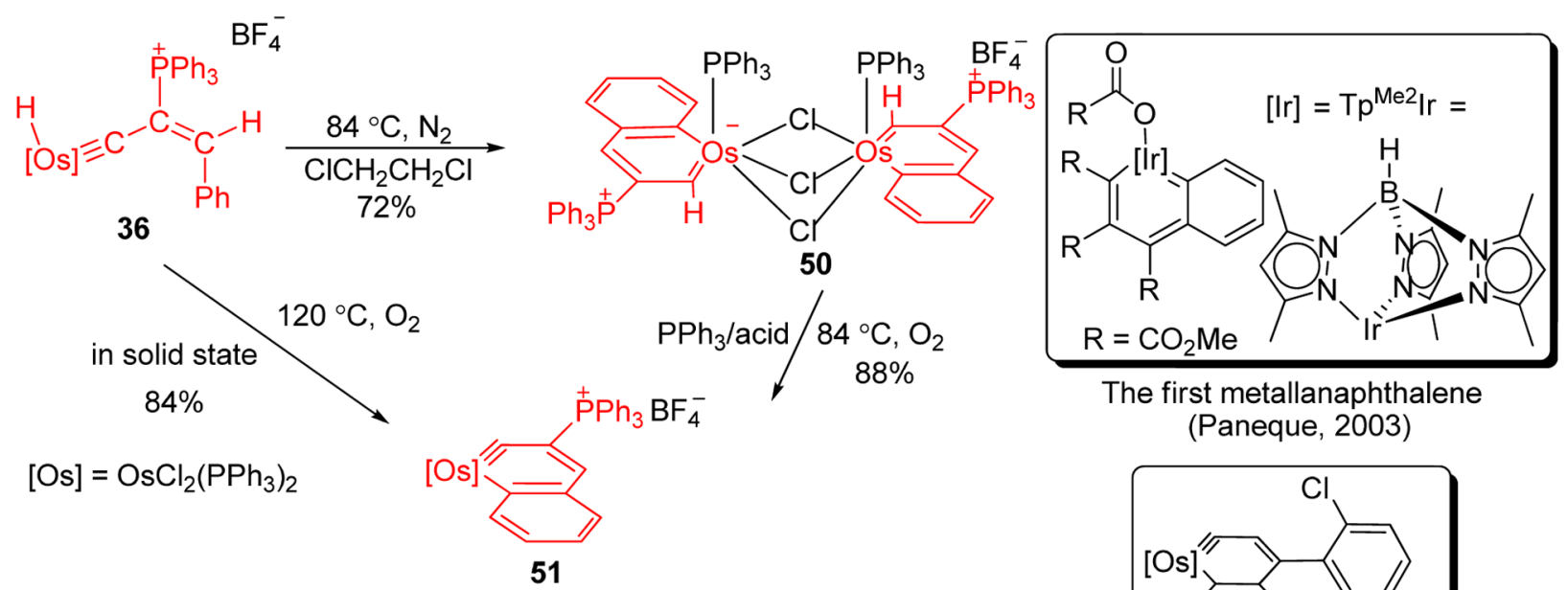

The first metallanaphthalene (Paneque, 2003)

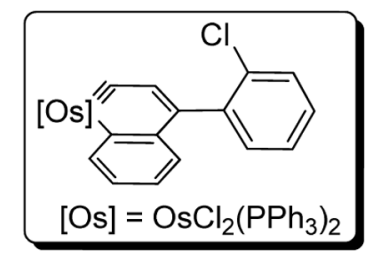

The first metallanaphthalyne (Jia and Lin, 2007)

49 (Scheme 17). ${ }^{42}$ The osmacycles 48 and 49 can be regarded as intermediates stabilized by an internal coordinated olefin, leading to the olefin metathesis or alkyne polymerization.

\section{Osmanaphthalene and Osmanaphthalyne}

Paneque et al. prepared the first metallanaphthalene in 2003 (Scheme 18, right). ${ }^{26}$ Jia, Lin, and co-workers synthesized the first metallanaphthalyne in 2007 (Scheme 18, right). ${ }^{43}$ We discovered the synthesis of osmanaphthalene and osmanaphthalyne unexpectedly in 2009, when we studied the thermal and air stability of osmium hydride alkenylcarbyne $36 .{ }^{44}$ Heating 36 in $\mathrm{ClCH}_{2} \mathrm{CH}_{2} \mathrm{Cl}$ under a $\mathrm{N}_{2}$ atmosphere afforded the $(u \text { - } \mathrm{Cl})_{3}$-bridged bisosmanaphthalene 50, while under an $\mathrm{O}_{2}$ atmosphere osmanaphthalyne $\mathbf{5 1}$ was produced. Interestingly, $\mathbf{5 1}$ could even be obtained by directly heating the solid sample of $\mathbf{5 0}$ in air (Scheme 18). ${ }^{44}$ The formation of $\mathbf{5 0}$ and $\mathbf{5 1}$ underwent a similar migration of the hydride ligand from the osmium center to the carbyne carbon atom. The subsequent ortho $\mathrm{C}-\mathrm{H}$ bond activation of the phenyl ring led to the formation of a hydride osmanaphthalene intermediate. The reaction then began to diverge depending on the atmosphere. Under a $\mathrm{N}_{2}$ atmosphere, the dimerization dominated, and an $\mathrm{O}_{2}$ 
SCHEME 19

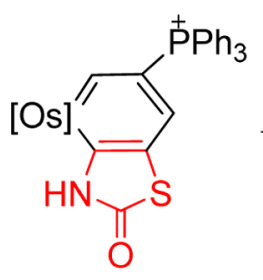

52

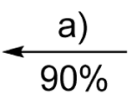

[Os]<smiles>CCc1sc(OC)nc1[AlH2]</smiles>

16

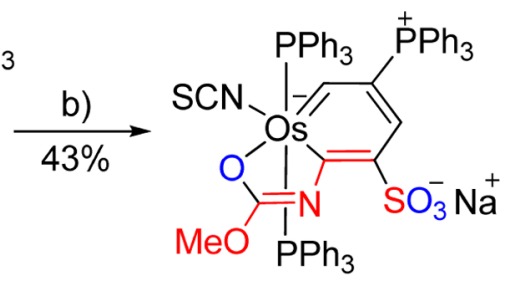

53

$$
[\mathrm{Os}]=\left[\mathrm{Os}\left(\mathrm{PPh}_{3}\right)_{2}(\mathrm{NCS})_{2}\right]^{-}
$$

a) $\mathrm{CHCl}_{3} / \mathrm{H}_{2} \mathrm{O}$, Reflux;

b) (i) $\mathrm{AgNO}_{3} / \mathrm{H}_{2} \mathrm{O}$, THF, RT; (ii) $\mathrm{NaOH} / \mathrm{CH}_{2} \mathrm{Cl}_{2}$, RT.

atmosphere led to the oxidation of the osmanaphthalene intermediate, yielding osmanaphthalyne 51. Notably, bisosmanaphthalene $\mathbf{5 0}$ could also be converted to osmanaphthalyne $\mathbf{5 1}$ in the presence of acids $\left(\mathrm{HCl}\right.$ and $\left.\mathrm{HBF}_{4}\right)$, $\mathrm{PPh}_{3}$, and $\mathrm{O}_{2}$. Because osmanaphthalene $\mathbf{5 0}$ and osmanaphthalyne $\mathbf{5 1}$ contained a metallabenzene segment and a metallabenzyne segment, respectively, the transformation from $\mathbf{5 0}$ to $\mathbf{5 1}$ represented the first example of the conversion from metallabenzene to metallabenzyne. The Jia group has realized the conversion from metallabenzyne to metallabenzene; ${ }^{45}$ hence we completed the formal interconversion of metallabenzene and metallabenzyne.

\section{Osmabenzothiazolone and Osmabenzoxazole}

As mentioned above, osmabenzothiazole $\mathbf{1 6}$ was formed through an intramolecular $S_{N} A r$ reaction. Heating 16 in wet chloroform gave osmabenzothiazolone 52 (Scheme 19), ${ }^{25}$ as a result of the hydrolysis of the methoxy group on the thiazole ring. When osmabenzothiazole $\mathbf{1 6}$ was treated with silver nitrate and then $\mathrm{NaOH}$, another fused metallaaromatic compound, osmabenzoxazole sulfonate $\mathbf{5 3}$, was obtained (Scheme 19). ${ }^{25}$ The formation of $\mathbf{5 3}$ involved the oxidation and ring-opening of the thiazole moiety. The subsequent coordination of the ester carbonyl oxygen atom to the osmium center formed the new oxazole ring. Our results represented the first metallathiazole, metallabenzothiazolone, and metallabenzoxazole.

\section{Concluding Remarks}

Over the past 8 years, we have developed a series of synthetic methods toward aromatic osmacycles. Our reactions are characterized by the alkyne coordination and subsequent nucleophilic attack by a triphenylphosphine, producing a great variety of osma-aromatics with phosphonium substituents. These substituents are critical because they stabilize both the intermediates and products, making it possible to isolate and use them as starting materials for the construction of osma-aromatics with new topologies. We have completed three possible retrosyntheses to sixmembered metallacycles (i.e., [5+1], [4 +2$]$, and [3 + 3]). The concept of the interconversion of metallacycles, such as the interconversion of metallabenzene and metallabenzyne, as well as isometallabenzene and metallabenzyne, has also been proposed and realized. Our metalla-aromatics include both monocycles and polycycles, with the transition metal either in the bridge or not in the bridge. We have demonstrated that the formal replacement of a $\mathrm{CH}$ segment (or C atom) in a conjugated cyclic system by an Os fragment not only can maintain aromaticity (as in metallabenzene and metallafuran) but also can overcome extreme strain in aromatic organic analogues (as in metallabenzyne and metallapyridyne).

The extraordinarily rich chemistry and diversified structures of our osma-aromatics corroborate the importance of metalla-aromatics, which remain as an active area of exploration; this field should have a bright and rapidly evolving future. On the other hand, the good stability of our osmacycles in air, water, and heat may enable their potential applications as materials. We have investigated, for the first time, the optical, ${ }^{25}$ electrochemical, ${ }^{15,30}$ and magnetic ${ }^{36}$ properties of these intriguing metalla-aromatics. Some of these properties are promising for use in materials science. We envision that the different substituents, metals, organic fragments, and ligands will further expand the family of metalla-aromatics, thus creating a multitude of candidates for various applications in the field of material science.

We are grateful to many co-workers who have contributed to the work described in this Account. Funding has been provided by the National Basic Research Program of China (973 Program, 
No. 2012CB821600), National Natural Science Foundation of China, Program for Changjiang Scholars and Innovative Research Team in University (PCSIRT), and Minjiang Scholar Program.

\section{BIOGRAPHICAL INFORMATION}

Xiao-Yu Cao obtained his B.S. in chemistry from Peking University in 2003. From 2004 to 2011, he worked with Prof. Jean-Marie Lehn in Université de Strasbourg, France, for his Ph.D. and with Prof. E. W. (Bert) Meijer in Eindhoven University of Technology, The Netherlands, as a Marie-Curie Intra-European Fellow. In 2011, he joined Xiamen University as an Associate Professor. His research focuses on the design, synthesis, controllable assembly, and applications of novel aromatic molecules.

Qianyi Zhao received her B.S. in chemistry from Henan Normal University in 2007 and her Ph.D. from Xiamen University in 2012, under the supervision of Prof. Haiping Xia. Now she works at Henan Normal University and is focusing on design, synthesis, and application of metal-boron compounds.

Zhiqun Lin received his B.S. in materials chemistry from Xiamen University in 1995, his M.S. in Macromolecular Science from Fudan University in 1998, and his Ph.D. in Polymer Science and Engineering from University of Massachusetts, Amherst, in 2002. He was a postdoctoral associate at UIUC from 2002 to 2004. He joined the Department of Materials Science and Engineering at lowa State University in 2004 and was promoted to Associate Professor in 2010. He moved to Georgia Institute of Technology in 2011. His research focuses on organic-inorganic nanocomposites, block copolymers, conjugated polymers, multifunctional nanocrystals, solar cells, and hierarchical structure formation and assembly.

Haiping Xia obtained his B.S. in chemistry in 1983, his M.S. in 1986, and his Ph.D. in 2002 from Xiamen University. He started to work at Xiamen University in 1986 and was promoted to Associate Professor in 1991, and Professor in 1999. In 2009, he received the National Natural Science Funds for Distinguished Young Scholar of China. His research focuses on the synthesis, reactivity, and applications of metalla-aromatics.

\section{FOOTNOTES}

*E-mail address: zhiqun.lin@mse.gatech.edu.

*E-mail address: hpxia@xmu.edu.cn.

The authors declare no competing financial interest.

\section{REFERENCES}

1 Landorf, C. W.; Haley, M. M. Recent Advances in Metallabenzene Chemistry. Angew. Chem., Int. Ed. 2006, 45, 3914-3936.

2 Wright, L. J. Metallabenzenes and Metallabenzenoids. Dalton Trans. 2006, 1821-1827.

3 He, G.; Xia, H.; Jia, G. Progress in the Synthesis and Reactivity Studies of Metallabenzenes. Chin. Sci. Bull. 2004, 49, 1543-1553.

4 Bleeke, J. R. Metallabenzenes. Chem. Rev. 2001, 101, 1205-1227.

5 Chen, J.; Jia, G. Recent Development in the Chemistry of Transition Metal-Containing Metallabenzenes and Metallabenzynes. Coord. Chem. Rev. 2013, 257, 2491-2521.

6 Thom, D. L.; Hoffmann, R. Delocalization in Metallocycles. Nouv. J. Chim. 1979, 3, $39-45$.

7 Elliott, G. P.; Roper, W. R.; Waters, J. M. Metallocyclohexatrienes or Metallabenzenes. Synthesis of Osmabenzene Derivatives and X-ray Crystal Structure of Carbonylbis(triphenylphosphine)thiabicycloosmaheptatriene. J. Chem. Soc., Chem. Commun. 1982, 811-813.
8 Jia, G. Recent Progress in the Chemistry of Osmium Carbyne and Metallabenzyne Complexes. Coord. Chem. Rev. 2007, 251, 2167-2187.

9 Jia, G. Progress in the Chemistry of Metallabenzynes. Acc. Chem. Res. 2004, 37, 479-486.

10 Xia, H.; He, G.; Zhang, H.; Wen, T. B.; Sung, H. H. Y.; Williams, I. D.; Jia, G. Osmabenzenes from the Reactions of $\mathrm{HC} \equiv \mathrm{CCH}(\mathrm{OH}) \mathrm{C} \equiv \mathrm{CH}$ with $\mathrm{OsX}_{2}\left(\mathrm{PPh}_{3}\right)_{3}(\mathrm{X}=\mathrm{Cl}, \mathrm{Br})$. J. Am. Chem. Soc. 2004, 126, 6862-6863.

11 Feixas, F.; Matito, E.; Poater, J.; Solà, M. Metalloaromaticity. Wiley Interdiscip. Rev.: Comput. Mol. Sci. 2013, 3, 105-122.

12 Fernández, l.; Frenking, G. Aromaticity in Metallabenzenes. Chem. -Eur. J. 2007, 13, 5873-5884.

13 Bleeke, J. R. Aromatic Iridacycles. Acc. Chem. Res. 2007, 40, 1035-1047.

14 Bleeke, J. R. Metallabenzene Chemistry. Acc. Chem. Res. 1991, 24, 271-277.

15 Zhang, H.; Wu, L.; Lin, R.; Zhao, Q.; He, G.; Yang, F.; Wen, T. B.; Xia, H. Synthesis, Characterization and Electrochemical Properties of Stable Osmabenzenes Containing $\mathrm{PPh}_{3}$ Substituents. Chem. -Eur. J. 2009, 15, 3546-3559.

16 Gong, L.; Lin, Y.; Wen, T. B.; Zhang, H.; Zeng, B.; Xia, H. Formation of Four Conjugated Osmacyclic Species in a One-Pot Reaction. Organometallics 2008, 27, 2584-2589.

17 Gong, L.; Chen, Z.; Lin, Y.; He, X.; Wen, T. B.; Xu, X.; Xia, H. Osmabenzenes from Osmacycles Containing an $\eta^{2}$-Coordinated Olefin. Chem. - Eur. J. 2009, 15, 6258-6266.

18 Zhang, H.; Xia, H.; He, G.; Wen, T. B.; Gong, L.; Jia, G. Synthesis and Characterization of Stable Ruthenabenzenes. Angew. Chem., Int. Ed. 2006, 45, 2920-2923.

19 Johns, P. M.; Roper, W. R.; Woodgate, S. D.; Wright, L. J. Thermal Rearrangement of Osmabenzenes to Osmium Cyclopentadienyl Complexes. Organometallics 2010, 29, 5358-5365

20 Clark, G. R.; Ferguson, L. A.; McIntosh, A. E.; Söhnel, T.; Wright, L. J. Functionalization of Metallabenzenes through Nucleophilic Aromatic Substitution of Hydrogen. J. Am. Chem. Soc. 2010, 132, 13443-13452.

21 Clark, G. R.; Johns, P. M.; Roper, W. R.; Wright, L. J. An Osmabenzofuran from Reaction between $\mathrm{Os}(\mathrm{PhC} \equiv \mathrm{CPh})(\mathrm{CS})\left(\mathrm{PPh}_{3}\right)_{2}$ and Methyl Propiolate and the C-Protonation of this Compound to Form a Tethered Osmabenzene. Organometallics 2006, 25, 1771-1777.

22 Elliott, G. P.; Mcauley, N. M.; Roper, W. R. An Osmium Containing Benzene Analog, Os(CSCHCHCHCH)(CO)( $\left(\mathrm{PPh}_{3}\right)_{2}$, Carbonyl(5-thioxo-1,3-pentadiene-1,5-diyl-C $\left.\mathrm{C}^{1}, \mathrm{C}^{5}, \mathrm{~S}\right)$-bis(triphenylphosphine)osmium, and Its Precursors. Inorg. Synth. 1989, 26, 184-189.

23 Gong, L.; Lin, Y.; He, G.; Zhang, H.; Wang, H.; Wen, T. B.; Xia, H. Synthesis and Characterization of an Air-Stable p-Osmaphenol. Organometallics 2008, 27, 309-311.

24 Rickard, C. E. F.; Roper, W. R.; Woodgate, S. D.; Wright, L. J. Electrophilic Aromatic Substitution Reactions of a Metallabenzene: Nitration and Halogenation of the Osmabenzene [Os $\left.\{\mathrm{C}(\mathrm{SMe}) \mathrm{CHCHCHCH}\}(\mathrm{CO})\left(\mathrm{PPh}_{3}\right)_{2}\right]$. Angew. Chem., Int. Ed. 2000, 39, 750-752.

25 Wang, T.; Li, S.; Zhang, H.; Lin, R.; Han, F.; Lin, Y.; Wen, T. B.; Xia, H. Annulation of Metallabenzenes: From Osmabenzene to Osmabenzothiazole to Osmabenzoxazole. Angew. Chem., Int. Ed. 2009, 48, 6453-6456.

26 Paneque, M.; Posadas, C. M.; Poveda, M. L.; Rendón, N.; Salazar, V.; Oñate, E.; Mereiter, K. Formation of Unusual Iridabenzene and Metallanaphthalene Containing Electron-Withdrawing Substituents. J. Am. Chem. Soc. 2003, 125, 9898-9899.

27 Zhang, H.; Lin, R.; Hong, G.; Wang, T.; Wen, T. B.; Xia, H. Nucleophilic Aromatic Addition Reactions of the Metallabenzenes and Metallapyridinium: Attacking Aromatic Metallacycles with Bis(diphenylphosphino)methane to Form Metallacyclohexadienes and Cyclic $\eta^{2}$-Allene-Coordinated Complexes. Chem. - Eur. J. 2010, 16, 6999-7007.

28 Lin, R.; Zhao, J.; Chen, H.; Zhang, H.; Xia, H. Interconversion of Metallabenzenes and Cyclic $\eta^{2}$-Allene-Coordinated Complexes. Chem. -Asian J. 2012, 7, 1915-1924.

29 Zhu, J.; Jia, G.; Lin, Z. Understanding Nonplanarity in Metallabenzene Complexes. Organometallics 2007, 26, 1986-1995.

30 Huang, J.; Lin, R.; Wu, L.; Zhao, Q.; Zhu, C.; Wen, T. B.; Xia, H. Synthesis, Characterization, and Electrochemical Properties of Bisosmabenzenes Bridged by Diisocyanides. Organometallics 2010, 29, 2916-2925.

31 Wen, T. B.; Zhou, Z. Y.; Jia, G. Synthesis and Characterization of a Metallabenzyne. Angew. Chem., Int. Ed. 2001, 40, 1951-1954.

32 Barrio, P.; Esteruelas, M. A.; Oñate, E. Preparation and Characterization of an Isometallabenzene with the Structure of a 1,2,4-Cyclohexatriene. J. Am. Chem. Soc. 2004, 126, 1946-1947.

33 Zhao, Q.; Gong, L.; Xu, C.; Zhu, J.; He, X.; Xia, H. Stable Iso-osmabenzenes from a Formal $[3+3]$ Cycloaddition Reaction of Metal Vinylidene with Alkynols. Angew. Chem., Int. Ed. 2011, 50, 1354-1358.

34 Zhao, Q.; Zhu, J.; Huang, Z.-A.; Cao, X.-Y.; Xia, H. Conversions of Osmabenzyne and Isoosmabenzene. Chem. -Eur. J. 2012, 18, 11597-11603.

35 Weller, K. J.; Filippov, I.; Briggs, P. M.; Wigley, D. E. Pyridine Degradation Intermediates as Models for Hydrodenitrogenation Catalysis: Preparation and Properties of a Metallapyridine Complex. Organometallics 1998, 17, 322-329.

36 Liu, B.; Wang, H.; Xie, H.; Zeng, B.; Chen, J.; Tao, J.; Wen, T. B.; Cao, Z.; Xia, H. Osmapyridine and Osmapyridinium from a Formal [4 +2$]$ Cycloaddition Reaction. Angew. Chem., Int. Ed. 2009, 48, 5430-5434. 
37 Yu, N.; Wang, C. Y.; Zhao, F.; Liu, L. T.; Zhang, W. X.; Xi, Z. F. Diverse Reactions of 1,4-Dilithio-1,3-dienes with Nitriles: Facile Access to Tricyclic $\Delta^{1}$-Bipyrrolines, Multiply Substituted Pyridines, Siloles, and (Z,Z)-Dienylsilanes by Tuning of Substituents on the Butadienyl Skeleton. Chem.-Eur. J. 2008, 14 5670-5679.

38 Wang, T.; Zhang, H.; Han, F.; Lin, R.; Lin, Z.; Xia, H. Synthesis and Characterization of a Metallapyridyne Complex. Angew. Chem., Int. Ed. 2012, 51, 9838-9841.

39 Buil, M. a. L.; Esteruelas, M. A.; Garcés, K.; Oliván, M.; Oñate, E. $\mathrm{C}_{\beta}\left(\mathrm{sp}^{2}\right)-H$ Bond Activation of $\alpha, \beta$-Unsaturated Ketones Promoted by a Hydride-Elongated Dihydrogen Complex: Formation of Osmafuran Derivatives with Carbene, Carbyne, and NH-Tautomerized $\alpha$-Substituted Pyridine Ligands. Organometallics 2008, 27 , 4680-4690.

40 Zhang, H.; Lin, R.; Luo, M.; Xia, H. Synthesis and Characterization of Stable Osmafuran Starting from $\mathrm{HC} \equiv \mathrm{CCH}(\mathrm{OH}) \mathrm{C} \equiv \mathrm{CH}$ and OsHCl(CO)(PPh $)_{3}$. Sci. China: Chem. 2010, 53, 1978-1981.
41 Gong, L.; Lin, Y.; Wen, T. B.; Xia, H. Synthesis of Coordinated $\eta^{2}$ - $\alpha, \beta$-Unsaturated Ketone Osmacycles from an Osmium-Coordinated Alkyne Alcohol Complex. Organometallics 2009, 28, 1101-1111.

42 Lin, Y.; Gong, L.; Xu, H.; He, X.; Wen, T. B.; Xia, H. Nine-Membered Osmacycles Derived from Metathesis Reactions between Alkynes and an Osmafuran. Organometallics 2009 , 28, 1524-1533.

43 He, G.; Zhu, J.; Hung, W. Y.; Wen, T. B.; Sung, H. H.-Y.; Williams, I. D.; Lin, Z.; Jia, G. A Metallanaphthalyne Complex from Zinc Reduction of a Vinylcarbyne Complex. Angew. Chem., Int. Ed. 2007, 46, 9065-9068.

44 Liu, B.; Xie, H.; Wang, H.; Wu, L.; Zhao, Q.; Chen, J.; Wen, T. B.; Cao, Z.; Xia, H. Selective Synthesis of Osmanaphthalene and Osmanaphthalyne by Intramolecular C-H Activation. Angew. Chem., Int. Ed. 2009, 48, 5461-5464.

45 Hung, W. Y.; Zhu, J.; Wen, T. B.; Yu, K. P.; Sung, H. H. Y.; Williams, I. D.; Lin, Z.; Jia, G. Osmabenzenes from the Reactions of a Dicationic Osmabenzyne Complex. J. Am. Chem. Soc. 2006, 128, 13742-13752. 